\title{
Preemptive use of adjunctive IV lidocaine for enhanced recovery after abdominal hysterectomy for overweight and obese women: a prospective, randomized, double-blind, placebo-controlled study
}

\author{
Nahla Waer Shady ${ }^{1 *}$, Hassan Ahmed Farouk ${ }^{1}$, Hany Farouk Sallam²
}

\begin{abstract}
${ }^{1}$ Obstetrics and Gynecology Department, Aswan Faculty of Medicine, Aswan University, Aswan Governorate, Egypt ${ }^{2}$ Obstetrics and Gynecology Department, Mansoura Insurance Hospital, Mansoura, Egypt
\end{abstract}

Received: 08 January 2021

Accepted: 10 February 2021

\section{*Correspondence:}

Dr. Nahla Waer Shady,

E-mail: nahlagyn@yahoo.com

Copyright: () the author(s), publisher and licensee Medip Academy. This is an open-access article distributed under the terms of the Creative Commons Attribution Non-Commercial License, which permits unrestricted non-commercial use, distribution, and reproduction in any medium, provided the original work is properly cited.

\begin{abstract}
Background: This investigation planned to evaluate the clinical results of adjunctive IV lidocaine bolus dose plus infusion for one hour after surgery in patients who underwent an abdominal hysterectomy in obese and overweight women.

Methods: We performed a double-blind, placebo-controlled study, (ClinicalTrials.gov identifier: NC03748108), with patients undergoing abdominal hysterectomy divided into 2 groups: one group received intravenous lidocaine single bolus dose preoperatively and IV infusions till one hour after the surgical procedure, and the opposite received normal saline infusion (placebo). We assessed postoperative results, including pain scores rankings on a visual analog scale (VAS) in rest and movement, administration frequency of pethidine. Postoperative nausea and vomiting, the period of hospital stay (LOS), time to ambulate, and patient satisfaction at forty-eight hours had been evaluated. Chi-square test and Monte Carlo test have been used for comparison among groups.

Results: There were 120 patients in our study. The visual analog scale (VAS), pain scores, length of hospital stay (LOS), and administration frequency of pethidine were significantly lower in the lidocaine group. The total amount of consumed pethidine was significantly lower in the lidocaine than the placebo group. There was a significant reduction in post-operative pain which was assessed by visual analog scale (VAS) after 2,4,8,12, and 24 hours either during movement or during rest in the lidocaine group compared to the placebo group, $\mathrm{p}=(0.0001,0.0001,0.0001,0.0001$ and 0.0001).

Conclusions: The administration of adjuvant intravenous lidocaine infusion reduces pain during the postoperative period after abdominal hysterectomy, is associated with early recovery, decreased postoperative opioid analgesic requirement, and better patient satisfaction in overweight and obese women undergoing abdominal hysterectomy.
\end{abstract}

Keywords: Abdominal hysterectomy, Enhanced recovery, IV lidocaine

\section{INTRODUCTION}

Pain is a common problem after abdominal hysterectomy and may interfere with early movement and recovery. Therefore, the reduction of postoperative pain would enhance patient recovery postoperatively. ${ }^{1}$
Postoperative pain results because of releases of inflammatory, visceral, and neuropathic mediators because of surgical trauma creating anatomical and functional changes in pain pathways coming about in hyperalgesia and central sensitization. Successful relief of pain is the foundation of recovery from surgery. ${ }^{2}$ 
The prevalence of obesity described as a body mass index (BMI) $\geq 30 \mathrm{~kg} / \mathrm{m} 2$ is more prominent than $30 \%$ and maintains on growing (3). Obesity is associated with beneficiant technical difficulties and improved patient morbidity after open hysterectomy. Expanding BMI is associated with prolonged operative time, longer nonsurgical room time, higher assessed blood loss, and other operative complications. ${ }^{4,5}$

Current records have shown that the hazard of taking chronic opioids after surgical treatment will increase after approximately five days of postoperative opioid remedy. ${ }^{6,7}$ Limitation the use of narcotics is desirable, especially those with few or no systemic adverse drug effects (ADEs), and lidocaine is one such perioperative multimodal agent that has been used clinically for many years.

Effective nonopioid analgesics regarded to lessen opioid consumption after gynecologic surgery include pregabalin, gabapentin, nonsteroidal anti-inflammatory drugs, cyclooxygenase 2 inhibitors, and paracetamol. ${ }^{8}$ Lidocaine is an amide neighborhood anesthetic whose mechanism of action is the blockade of voltage-gated sodium channels and due to its enormously low efficiency compared to other nearby anesthetics, it is less toxic at clinically relevant doses than others, such as bupivacaine and ropivacaine. ${ }^{9}$

Our hypothesis that the use of adjunctive IV lidocaine as a bolus dose pre-operative followed with IV infusion onehour post-operative with other non-opioid analgesia enhances obese and overweight women recovery after abdominal hysterectomy.This study aimed to assess the clinical effect of preemptive use of adjunctive intravenous lidocaine IV bolus dose plus infusion for one hour after surgery in obese and overweight women patients who underwent abdominal hysterectomy.

\section{METHODS}

The current study is a clinically registered doubleblinded, parallel, randomized trial (ClinicalTrials.gov identifier: NC03748108), conducted in a tertiary university hospital, from December 1, 2018, to August 1, 2020. The institutional ethical review board approved the study (Aswu/203/2/18).

\section{Inclusion criteria}

Study inclusion criteria were overweight and obese women who underwent total abdominal hysterectomy (TAH) with or without bilateral salpingoo-oophorectomy (BSO) due to myoma, menorrhagia, metrorrhagia, and endometrial hyperplasia.

\section{Exclusion criteria}

Patients with cardiac, hepatic, renal, or thromboembolic disease; patients with pelvic endometriosis and adnexal mass; patients with endometrial or cervical cancer, patient with an allergy to amid local anesthetic, and patients with chronic pelvic pain.

\section{Eligible participants}

150 patients were asked to participate, 30 patients were excluded, 24 patients not meeting inclusion criteria, and 6 patients refuse to participate. Therefore, the remaining 120 patients were included in the study.

All participants underwent detailed history, general, abdominal, and vaginal examinations, body mass index (BMI) was calculated, and pelvic ultrasound examination and preoperative hemoglobin were undertaken for all participants (Figure 1).

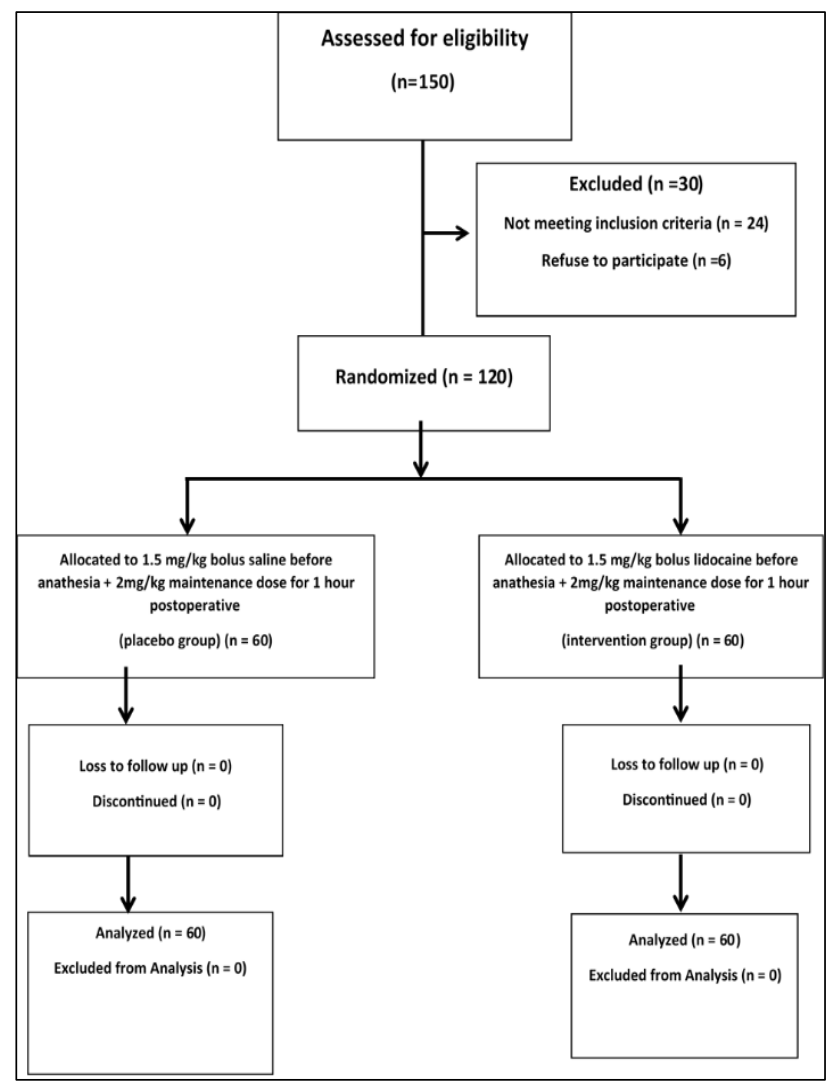

Figure 1: Flowchart of the study.

The participants who fulfilled the eligibility criteria were explained about the study with the beneficial and possible adverse effects of lidocaine. Informed written consent was obtained from them, after that participants were randomized to two groups

Group (1) 60 patients received normal saline infusion (placebo) single bolus dose $1.5 \mathrm{mg} / \mathrm{kg}$ saline preoperatively and IV infusion $2 \mathrm{mg} / / \mathrm{kg} / \mathrm{h}$ till one hours after the surgery. Group (2) 60 patients received intravenous lidocaine single bolus dose $1.5 \mathrm{mg} / \mathrm{kg}$ lidocaine $2 \%$ preoperatively and IV infusion $2 \mathrm{mg} / \mathrm{kg} / \mathrm{h}$ till one hours after the surgery, 


\section{Randomization}

Patients were randomized to two groups, each comprising of 60 patients according to a two-blocked randomization list which was coded (1 or 2) at a 1:1 ratio. The two equal groups were prepared using a computer-generated randomization framework. The assigned groups will be concealed in sequentially numbered fixed hazy envelopes that might be opened after enrollment.

Patient allocation will be performed before the induction of anesthesia by a free individual, who will not in any case be associated with this investigation. Participating patients, surgeons, anesthesiologists, and medical investigators who were involved in the data collection were all blinded to the patient's group assignment until the collection of data for all cases was complete.

\section{Intervention}

In all eligible participants, the hysterectomies were performed by the same operative team. Patients were randomized to two groups, Group (1) 60 patients received normal saline infusion (placebo) single bolus dose $1.5 \mathrm{mg} / \mathrm{kg}$ saline preoperatively and IV infusion $2 \mathrm{mg} / / \mathrm{kg} / \mathrm{h}$ till one hour after the surgery.

Group (2) 60 patients received intravenous lidocaine single bolus dose $1.5 \mathrm{mg} / \mathrm{kg}$ lidocaine $2 \%$ preoperatively and IV infusion $2 \mathrm{mg} / / \mathrm{kg} / \mathrm{h}$ till one hours after the surgery.

Prophylactic antibiotic (cefazolin $1 \mathrm{~g}$ or ceftriaxone $1 \mathrm{~g}$ ) was given $30 \mathrm{~min}$ before scrubbing of the patient. The hemostatic strategy during surgery was done by conventional stitch ligature, using vicryl stitches (Vicryl 1-0 polyglactin; Egycryl, Taisier CO, Egypt) only. ${ }^{9,10}$

The abdomen was exposed through Pfannenstiel incision, and after skin incision, the subcutaneous fat and abdominal fascia were opened crosswise, and the rectus muscle was opened on the midline. Total hysterectomy with or without bilateral salpingo-oophorectomy was done. Anesthesia protocol and surgical procedure were the same in both groups.

Anesthesia was initiated quickly with intravenous thiopental $(5 \mathrm{mg} / \mathrm{kg})$ and succinylcholine (1.5 mg kg1); at that point, a cuffed endotracheal tube was inserted. Anesthesia continued with a mixture of $50 \%$ NO, 50\% $\mathrm{O} 2$, and 0.5 to $0.75 \mathrm{MAC}$ isoflurane at a flow of $5 \mathrm{~L}$ min1. Paralysis was maintained with $0.5 \mathrm{mg} \mathrm{kg} 1$ atracurium. Anesthesia was augmented by administering $100 \mathrm{~kg}$ fentanyl and $2 \mathrm{mg}$ midazolam while continuing the volatile anesthetic. All ladies got $3 \mathrm{mg}$ of intravenous morphine at the end of the operation.

Before surgery, eligible women were instructed by a nurse anesthetist and a final year medical student on how to rate their pain during rest and movement on a visual analog scale (VAS) at 2, 4, 8, 12, and $24 \mathrm{~h}$ after their operation. VAS ranges from 0 (no pain) to 10 (most intense pain ever).

VAS recordings were translated into numerical pain scores by the medical student. Women were administered a $100 \mathrm{mg}$ diclofenac suppository every 8 hours after surgery and were administered pethidine $3 \mathrm{mg}$ each time when they reported a VAS score higher than $5 \mathrm{~cm}$. At 48 $\mathrm{h}$ post-operation, participants were asked whether they were satisfied with their pain control. Answers recorded just as 'Yes' or 'No.

\section{Study outcome}

VAS pain score levels during the $24 \mathrm{~h}$ after surgery was the primary endpoint of the study. The secondary outcomes were estimation of hospital stay, amount of postoperative opioid in form of pethidine, early ambulation from bed within 8 hours, time for both bowel movement and getting out of the first flatus, operative time, patient satisfaction with their pain control and side effects of lidocaine.

\section{Sample size}

The size of the study was based on detecting a difference of 1 in the mean VAS scores at $24 \mathrm{~h}$ post-operation between the two groups. With a two-tailed an of .05 and a power of $90 \%$, we needed 56 participants in each group. Expecting a maximum loss-to-follow-up of 5\%, we decided to recruit 60 participants in each group

\section{Statistical Analysis}

Data were entered and statistically analyzed using the Statistical Package for Social Sciences (SPSS) version 16. Qualitative data were described as numbers and percentages. Chi-square test and Monte Carlo test were used for comparison between groups, as appropriate. Quantitative data were described as means (SD) or medians, as appropriate.

They were tested for normality by the KolmogorovSmirnov test. In the normally distributed variables, oneway ANOVA with LSD posthoc multiple comparisons was used for comparison between groups. In the nonnormally distributed variables, the Kruskal-Wallis test and Mann Whitney test were used for comparison between groups, as appropriate. Odds ratios and their $95 \%$ confidence interval were calculated. "p-value $\leq 0.05$ " was considered to be statistically significant.

\section{RESULTS}

Our study started with 150 patients who were asked to participate, 30 patients were excluded, 24 patients not meeting inclusion criteria and 6 patients refuse to participate. Therefore the remaining 120 patients were randomized to 2 groups each group comprised of 60 
patients. Group I: (placebo group, undergone hysterectomy with a bolus dose of $1.5 \mathrm{mg} / \mathrm{kg}$ normal saline just before anesthesia $+2 \mathrm{mg} / \mathrm{kg}$ maintenance dose for 1 hour postoperative ), Group II: ( lidocaine group, undergone hysterectomy with a bolus dose of lidocaine $(1.5 \mathrm{mg} / \mathrm{kg})$ just before anesthesia and maintenance dose
(2 $\mathrm{mg} / \mathrm{kg}$ ) for 1 hour postoperative). There was no significant difference between the two groups corresponding to their age, weight, Hight, body mass index (BMI), uterine size, history of the previous scar, initial hemoglobin, and indication of hysterectomy (Table 1).

Table 1: Preoperative characteristics of women in the study groups.

\begin{tabular}{|llll|}
\hline Parameters & $\begin{array}{l}\text { Group I } \\
(\mathbf{n = 6 0})\end{array}$ & $\begin{array}{l}\text { Group II } \\
(\mathbf{n = 6 0})\end{array}$ & Significance \\
\hline Age $($ year) & $50.08 \pm 5.44$ & $50.2 \pm 5.15$ & 0.852 \\
\hline Weight $(\mathbf{k g})$ & $87 \pm 7.9$ & $86.4 \pm 7.6$ & 0.428 \\
\hline Height $(\mathbf{c m})$ & $163.73 \pm 4.16$ & $163.42 \pm 4.47$ & 0.752 \\
\hline BMI & $28.86 \pm 2.76$ & $28.7 \pm 2.39$ & 0.732 \\
\hline Previous scar $(\%)$ & $22(36.7)$ & $21(35)$ & 0.651 \\
\hline Uterus size (weeks) & $13.17 \pm 3.38$ & $13.17 \pm 3.22$ & 0.831 \\
\hline $\begin{array}{l}\text { Initial hemoglobin indication of } \\
\text { hysterectomy }(\%)\end{array}$ & $10.38 \pm 0.80$ & $10.34 \pm 0.84$ & 0.627 \\
\hline AUB & $23(38.3)$ & $21(35)$ & \\
\hline Adenomyosis & $8(13.3)$ & $7(11.7)$ & 0.923 \\
\hline Endometrial hyperplasia & $9(15)$ & $8(13.3)$ & \\
\hline Endometrial polyp & $3(5)$ & $5(8.3)$ & \\
\hline Myoma & $17(28.3)$ & $19(31.7)$ & \\
\hline
\end{tabular}

BMI (body mass index), AUB (abnormal uterine bleeding), \# Variables are presented as mean and standard deviation, and number (percentage).

Table 2: postoperative VAS during movement and rest in the study groups.

\begin{tabular}{|c|c|c|c|}
\hline \multirow{2}{*}{ VAS } & Group I & Group II & \multirow{2}{*}{ Significance } \\
\hline & $(n=60)$ & $(n=60)$ & \\
\hline \multicolumn{4}{|c|}{ VAS during movement } \\
\hline 2 hours & $8.9 \pm 1.01$ & $7.48 \pm 1.08$ & $0.0001 *$ \\
\hline 4 hours & $8.2 \pm 0.94$ & $6.12 \pm 0.96$ & $0.0001 *$ \\
\hline 8 hours & $7.2 \pm 0.99$ & $4.55 \pm 0.99$ & $0.0001 *$ \\
\hline 12 hours & $6.55 \pm 0.999$ & $3.3 \pm 0.38$ & $0.0001 *$ \\
\hline 24 hours & $5(3-7)$ & $2(0-3)$ & $0.0001 *$ \\
\hline \multicolumn{4}{|c|}{ VAS during rest } \\
\hline 2 hours & $6.73 \pm 1.07$ & $4.95 \pm 1.19$ & $0.0001 *$ \\
\hline 4 hours & $6(2-8)$ & $3(0-6)$ & $0.0001 *$ \\
\hline 8 hours & $4(0-7)$ & $2(0-4)$ & $0.0001 *$ \\
\hline 12 hours & $3(0-5)$ & $0.5(0-3)$ & $0.0001 *$ \\
\hline 24 hours & $1(0-3)$ & $0(0-2)$ & $0.0001 *$ \\
\hline
\end{tabular}

VAS (visual analog scale). *Statistically Significant Difference, \# Variables are presented as mean and standard deviation, and median (minimum-maximum)

There was a great significant reduction in post-operative pain which was assessed by visual analog scale (VAS) after 2,4,8,12 and 24 hours either during movement or during rest in group II compared to group I, $\mathrm{p}=(0.0001$, $0.0001,0.0001,0.0001$ and 0.0001) (Table 2).Group II showed a significant decrease in hospital stays with a median of 2 days compared to the median 3 days in group1.p $=(0.0001)$ Also group II consumed less amount of postoperative opioid in form of pethidine, 19 (31.4\%) patients compared to $49(81.7 \%)$ patients in group I, $\mathrm{p}=(0.0001)$.
Table 3: Postoperative outcome in the study groups.

\begin{tabular}{|c|c|c|c|}
\hline Variables & $\begin{array}{l}\text { Group I } \\
(\mathbf{n}=60)\end{array}$ & $\begin{array}{l}\text { Group II } \\
(\mathbf{n}=\mathbf{6 0})\end{array}$ & Significance \\
\hline $\begin{array}{l}\text { Operative } \\
\text { time }\end{array}$ & $94.42 \pm 9.7$ & $95.12 \pm 10.07$ & 0.764 \\
\hline $\begin{array}{l}\text { Hospital stay } \\
\text { (median) } \\
\text { (minimum- } \\
\text { maximum) }\end{array}$ & $3(2-4)$ & $2(1-3)$ & $0.0001 *$ \\
\hline $\begin{array}{l}\text { Pethidine } \\
\text { consumption } \\
(\%)\end{array}$ & $\begin{array}{l}49 \\
(81.7)\end{array}$ & $19(31.7)$ & $0.0001 *$ \\
\hline $\begin{array}{l}\text { Early } \\
\text { ambulation } \\
(\%)\end{array}$ & $18(30)$ & $40(66.7)$ & $0.0001 *$ \\
\hline $\begin{array}{l}\text { Bowel } \\
\text { movement }\end{array}$ & $\begin{array}{l}14.92 \pm 3 \\
.54\end{array}$ & $9.58 \pm 2.17$ & $0.0001 *$ \\
\hline First flatus & $\begin{array}{l}33.14 \pm 6 \\
.43\end{array}$ & $17.47 \pm 3.49$ & $0.0001 *$ \\
\hline $\begin{array}{l}\text { Patients } \\
\text { satisfaction }\end{array}$ & $\begin{array}{l}19 \\
(31.7)\end{array}$ & 49 (81.7) & 0.375 \\
\hline $\begin{array}{l}\text { Distention } \\
(\%)\end{array}$ & $5(8.3)$ & $2(3.3)$ & 0.375 \\
\hline Fever $(\%)$ & $2(3.3)$ & $1(1.7)$ & 0.775 \\
\hline Nausea (\%) & $3(5)$ & $4(6.7)$ & 0.909 \\
\hline Vomiting (\%) & $2(3.3)$ & $1(1.7)$ & 0.775 \\
\hline Diarrhea (\%) & $1(1.7)$ & $0(0)$ & 1 \\
\hline
\end{tabular}

*Statistically Significant Difference, \# Variables are presented as mean and standard deviation, median (minimum-maximum), and number (percentage) 
The incidence of early ambulation from bed within 8 hours was increased in group II $40(66.7 \%)$ patients compared with $18(30 \%)$ patients in group $\mathrm{I}, \mathrm{p}=(0.0001)$. There was a significant reduction in time for both bowel movement and getting out of the first flatus in group II compared with group I, as the mean hours of bowel movement was $(9.58 \pm 2.17)$ in group II despite $(14.92 \pm 3.54)$ in group I, and the mean hours of getting out the first flatus were $(17.47 \pm 3.49)$ in group II compared to $(33.17 \pm 6.43)$ in group $\mathrm{I}, \mathrm{p}=(0.0001$ and $0.0001)$. Also, no of patients satisfied with their pain was a significant increase in lidocaine group $49(81.7 \%)$ patients compared to $19(31.4 \%)$ patients in the placebo group. $\mathrm{p}=(0.0001)$.

There were no significant differences concerning operative time and side effects in form of abdominal distention, fever, nausea, vomiting, and diarrhea in both groups. $\mathrm{p}=(0.764,0.375,0.775,0.909,0.775$ and 1.00) respectively Table (3).

\section{DISCUSSION}

There are 4 unique aspects of the ERAS protocol after surgical treatment, anesthetic desire, nonopioid multimodal pain control, postoperative nausea, and vomiting (PONV) prevention strategies, and fluid control. In the hour study, we examine the adjuvant lidocaine to the nonopioid analgesia to enhance the recovery of the obese and overweight affected person undergoing abdominal hysterectomy.

Our principal finding was that adjunctive bolus dose plus IV infusion of lidocaine may provide improvement in pain ratings in the perioperative period, decrease inhospital stay, less amount of postoperative opioid in the form of pethidine, more early ambulation from bed within 8 hours, reduction in time for both bowel movement and getting out of the first flatus compared with placebo in overweight and obese women undergoing abdominal hysterectomy.

These findings demonstrate that lidocaine can be used to enhance recovery and reduce postoperative pain. To the best of our knowledge, this study is the first double-blind randomized placebo-controlled trial comparing the effectiveness of adjunctive bolus dose plus IV infusion of lidocaine versus placebo for enhanced recovery after abdominal hysterectomy for overweight and obese women.

There are varied ways by which intravenous lidocaine lessens the postoperative pain and enhance the recovery process in the perioperative period. Also, has been broadly detailed and is multifactorial. Expansion in a grouping of acetylcholine in cerebrospinal liquid, prompting worsening of inhibitory sliding pain pathway, (10) hindering of muscarinic receptors M3, restraint of glycine receptors, arrival of endogenous opioids, decrease of the incendiary reaction to tissue ischemia, and diminished arrival of cytokines because of tissue damage, are a portion of the components proposed for the painrelieving impacts of lignocaine implantation.,10-14 Lidocaine is additionally answerable for an immediate or backhanded decrease of postsynaptic depolarization interceded by $\mathrm{N}$ methy $\mathrm{D}$ aspartate receptors. ${ }^{15}$

Our results were also following findings from Tauzin Fin and Bernard who examined the impact of adding lidocaine infusion to standard anesthesia protocol in an aggregate of 47 patients admitted in two phases and planned for laparoscopic nephrectomy. Lidocaine infusion was continued for $24 \mathrm{~h}$ postoperatively and was associated with significantly reduced morphine consumption and postop pain score and hyperalgesia extent on days 1,2 , and 4 postoperatively. Brief walk test and entry of first flatus were additionally altogether improved in quite a while getting iv lidocaine infusion. Comparative outcomes were seen by Kim et al. and by Yon et al. ${ }^{16-18}$

Meta-analyses and systematic reviews detailed that IV lidocaine infusions diminished postoperative pain, diminished narcotic utilization, prompted a quicker return of bowel function, and abbreviated hospital length of stay in abdominal surgeries. ${ }^{19,20}$ However, investigations of patients going through open hysterectomy have not demonstrated advantages in reducing pain scores, narcotic utilization, improving quality of recovery, or shortening hospital stays, except for some reduction in inflammatory mediators and pain scores in the early postoperative period in 1 study. ${ }^{21-23}$ The absence of painrelieving advantage might be because the lidocaine infusions were utilized uniquely in the intraoperative period in these studies. In our study, we extend the lidocaine infusion for one hour's post-operative. Albeit numerous studies of other abdominal surgeries proceeded with the lidocaine implantation in the postoperative period, a few examinations likewise detailed advantage after administration just in the intraoperative period. ${ }^{12}$

Opioid-sparing analgesic regimens are believed to be a crucial part of an ERAS protocol, due to the fact opioids had been implicated in immunosuppression, postoperative hyperalgesia, submit-operative nausea, and vomiting (PONV), paralytic ileus, and delay of early mobilization due to sedation. Our study display that using adjunctive lidocaine lessens the amount of postoperative opioid administration. Our study shows a reduction in time for both bowel movement and getting out of the first flatus compared with placebo.

Postoperative ileus is a typical purpose behind an extended hospital stay after abdominal hysterectomy, even when the surgical procedure straight forward without complication. Its pathophysiology is multifactorial. Arrival of inflammatory mediators during surgery, huge volume fluid resuscitation, increase the time of surgery, and postoperative utilization of narcotics for analgesia have been hypothesized as elements liable 
for ileus. Sedative agents, for example, narcotics are believed to be among the causal components. To lessen the stress response, the utilization of IV lidocaine has been advocated. This provides better postoperative pain control and decreases surgical stress. Moreover, it shortens the length of postoperative ileus. ${ }^{24-26}$

Early return of bowel function was hypothetical as unite of the criteria for fast track surgery and early discharge from hospital. Lidocaine through its effects on proinflammatory mediators was responsible for early bowel function after surgery. ${ }^{27,28}$ This effect was, however, in contrast to our result, not seen in patients undergoing peripheral and abdominal surgeries. ${ }^{29,30}$ Our study is in line with De Oliveira et al. who state that the utilization of intravenous lidocaine enhances the fasttrack surgery. ${ }^{31}$

One of the strengths of our study is that a double-blinded randomized trial full power to advocate the application of bolus dose of lidocaine plus iv infusion for one hour postoperative as an adjuvant to non-opioid analgesia effective for early recovery after abdominal hysterectomy in overweight and obese women. Another strength in our study is the simplicity of the technique of administration of lidocaine.

One of our limits of the study is the use of general anesthesia and not use of regional anesthesia, however no RCTs are delineating the ideal intraoperative anesthetic protocol to guide ERAS ideas, even in guidelines already installed for colorectal surgical procedure. Regardless, intraoperative neuraxial anesthesia has been implemented in multiple fast-track protocols because of proven benefits on attenuating the physiologic surgical stress response and showing narcotic saving impacts. Future studies are needed to delineate the post-operative benefit of lidocaine in adjunctive with regional anesthesia to enhance early recovery after gynecological surgery.

\section{CONCLUSION}

Intravenous lidocaine infusion reduces pain during the postoperative period after abdominal hysterectomy, is associated with early recovery, decreased postoperative analgesic requirement, and better patient satisfaction.

\section{Recommendations}

The purpose of this study was to describe the evidence for the benefits of Intravenous lidocaine infusion after surgery in patients who underwent an abdominal hysterectomy in obese and overweight women, our result indicates that intravenous lidocaine infusion reduces pain during the postoperative period after abdominal hysterectomy, is associated with early recovery, decreased postoperative analgesic requirement, and better patient satisfaction.

\section{ACKNOWLEDGMENTS}

Funding: No funding sources

Conflict of interest: None declared

Ethical approval: The study was approved by the

Institutional Ethics Committee

\section{REFERENCES}

1. Aarts JWM, Nieboer TE, Johnson N, Tavender E, Garry R, Mol BWJ, Kluivers KB. Surgical approach to hysterectomy for benign gynaecological disease. Cochrane Database Syst Rev. 2015;8:3677.

2. Nelson G, Altman AD, Nick A.. Guidelines for postoperative care in gynecologic/oncology surgery: Enhanced Recovery After Surgery (ERAS®) Society recommendations--Part II. Gynecol Oncol. 2016;140(2):323-32.

3. Lamvu G, Zolnoun D, Boggess J, Steege JF. Obesity: Physiologic changes and challenges during laparoscopy. Am J Obstet Gynecol. 2004;191:66974.

4. McMahon MD, Scott DM, Saks E, Tower A, Raker CA, Matteson KA. Impact of obesity on outcomes of hysterectomy. J Minim Invasive Gynecol. 2014;21:259-65.

5. Shah DK, Voorhis BJ, Vitonis AF, Missmer SA. Association between body mass index, uterine size, and operative morbidity in women undergoing minimally invasive hysterectomy. J Minim Invasive Gynecol. 2016;23:1113-22.

6. Tyan P, Amdur R, Berrigan M. Differences in postoperative morbidity among obese patients undergoing abdominal versus laparoscopic hysterectomy for benign indications. J Minim Invasive Gynecol. 2020;27:464-72.

7. Emad M. Association between obesity and the trends of routes of hysterectomy performed for benign indications. Obst Gynecol. 2015;125(4):912-8.

8. Shah A, Hayes CJ, Martin BC. Characteristics of initial prescription episodes and likelihood of longterm opioid use-United States, 2006-2015. Morbidity Mortality. 2017;66(10):265.

9. Marret E. Meta-analysis of intravenous lidocaine and postoperative recovery after abdominal surgery. British J Surgery. 2008;95(11):1331-8.

10. Markus WH. Inhibition of M3 muscarinic acetylcholine receptors by local anaesthetics. British J Pharmacol. 2001;133(1):207-16.

11. Gabriele B, Sotgiu ML. Central effects of systemic lidocaine mediated by glycine spinal receptors: An iontophoretic study in the rat spinal cord." Brain Res. 1993;603(2):201-6.

12. McCarthy GC, Megalla SA, Habib AS. Impact of intravenous lidocaine infusion on postoperative Analgesia and recovery from surgery. Drugs. 2010;70:1149-63.

13. Vigneault L, Turgeon AF, Côté D. Perioperative intravenous lidocaine infusion for postoperative pain 
control: a meta-analysis of randomized controlled trials. J Can Anesth. 2011;58:22-37.

14. Klaver, Manuela JM, Buckingham MG, George F. Lidocaine attenuates cytokine-induced cell injury in endothelial and vascular smooth muscle cells. Anesthesia Analgesia. 2003;97(2):465-70.

15. Nagy, Istvan, Clifford J. Lignocaine selectively reduces $\mathrm{C}$ fibre-evoked neuronal activity in rat spinal cord in vitro by decreasing N-methyl-D-aspartate and neurokinin receptor-mediated post-synaptic depolarizations; Implications for the development of novel centrally acting analgesics. Pain. 1996;64(1):59-70.

16. Fin P, Bernard O, Sesay M. Benefits of intravenous lidocaine on post-operative pain and acute rehabilitation after laparoscopic nephrectomy. J Anaesthesiol Clin Pharmacol. 2014;30(3):366-72.

17. Kim KT, Cho DC, Sung JK, Kim YB, Kang H, Song KS. Intraoperative systemic infusion of lidocaine reduces postoperative pain after lumbar surgery: A double blinded, randomized, placebo controlled clinical trial. Spine J. 2014;14:1559-66.

18. Yon JH, Choi GJ, Kang H, Park JM, Yang HS. Intraoperative systemic lidocaine for pre-emptive analgesics in subtotal gastrectomy: a prospective, randomized, double-blind, placebo-controlled study. Can J Surg. 2014;57(3):175-82.

19. Barbara C. The hypothesis that antagonism of fentanyl analgesia by 2-chloroprocaine is mediated by direct action on opioid receptors. Regional Anesthesia Pain Med. 1997;22(1):43-52.

20. Cohen SP, Mao J. Is the analgesic effect of systemic lidocaine mediated through opioid receptors? Acta Anaesthesiologica Scandinavica. 2003;47(7)910-1.

21. Klaver, Manuela JM, Buckingham MG, Rich GF. Lidocaine attenuates cytokine-induced cell injury in endothelial and vascular smooth muscle cells. Anesthesia Analgesia. 2003;97(2):465-70.

22. Istvan N, Woolf CJ. Lignocaine selectively reduces $\mathrm{C}$ fibre-evoked neuronal activity in rat spinal cord in vitro by decreasing N-methyl-D-aspartate and neurokinin receptor-mediated post-synaptic depolarizations; implications for the development of novel centrally acting analgesics. Pain. 1996;64(1):59-70.

23. Tauzin P, Bernard O, Sesay M. Benefits of intravenous lidocaine on post-operative pain and acute rehabilitation after laparoscopic nephrectomy. J Anaesthesiol Clin Pharmacol. 2014;30(3):366-72.

24. Snyder GL, Greenberg S. Effect of anaesthetic technique and other perioperative factors on cancer recurrence. Br J Anaesth. 2010;105:106-15.

25. Fletcher D, Martinez V. Opioid-induced hyperalgesia in patients after surgery: a systematic review and a meta-analysis. Br J Anaesth. 2014;112:991-1004.

26. Kumar L, Barker C, Emmanuel A. Opioid-induced constipation: pathophysiology, clinical consequences, and management. Gastroenterol Res Pract. 2014;1417-37.

27. Herroeder S, Pecher S, Schönherr ME. Systemic lidocaine shortens length of hospital stay after colorectal surgery: a double-blinded, randomized, placebo-controlled trial. Ann Surg. 2009;249(4):701.

28. Choi SJ, Kim MH, Jeong HY, Lee JJ. Effect of intraoperative lidocaine on anesthetic consumption, and bowel function, pain intensity, analgesic consumption and hospital stay after breast surgery. Korean J Anesthesiol. 2012;62(5):429-34.

29. Wuethrich PY, Romero J, Burkhard FC, Curatolo M. No benefit from perioperative intravenous lidocainein laparoscopic renal surgery: A randomised, placebo controlled study. Eur J Anaesthesiol. 2012;29:537-43.

30. Myles PS, Weitkamp B, Jones K, Melick J, Hensen S. Validity and reliability of a postoperative quality of recovery score: The QoR 40. Br J Anaesth. 2000;84:11-5.

31. Oliveira GS, Duncan K, Fitzgerald P. Systemic lidocaine to improve quality of recovery after laparoscopic bariatric surgery: a randomized doubleblinded placebo-controlled trial. Obes Surg. 2014;24:212-8 .

Cite this article as: Shady NW, Farouk HA, Sallam HF. Preemptive use of adjunctive IV lidocaine for enhanced recovery after abdominal hysterectomy for overweight and obese women: a prospective, randomized, double-blind, placebo-controlled study. Int J Reprod Contracept Obstet Gynecol 2021;10:1095-101. 